\title{
FGFR1 $\beta$ is a driver isoform of FGFR1 alternative splicing in breast cancer cells
}

This article has been corrected. Correction in Oncotarget. 2019; 10:7014-7015.

Ming Zhao ${ }^{1}$, Ming-Lei Zhuo ${ }^{2}$, Xiaofeng Zheng ${ }^{3}$, Xiaoping Su${ }^{3}$ and Funda MericBernstam ${ }^{1,4,5}$ ${ }^{1}$ Department of Investigational Cancer Therapeutics, The University of Texas MD Anderson Cancer Center, Houston, TX, USA
${ }^{2}$ Key Laboratory of Carcinogenesis and Translational Research, Department of Thoracic Medical Oncology-I, Peking University
Cancer Hospital and Institute, Beijing, China
${ }^{3}$ Department of Bioinformatics and Computational Biology, The University of Texas MD Anderson Cancer Center, Houston,
TX, USA
${ }^{4}$ Department of Breast Surgical Oncology, The University of Texas MD Anderson Cancer Center, Houston, TX, USA
${ }^{5}$ Institute of Personalized Cancer Therapy, The University of Texas MD Anderson Cancer Center, Houston, TX, USA
Correspondence to: Ming Zhao, email: mzhao6@mdanderson.org
Funda Meric-Bernstam, email: fmeric@mdanderson.org
Keywords: FGFR1; alternative splicing; breast cancer

Received: October 02, $2018 \quad$ Accepted: December 16, $2018 \quad$ Published: January 01, 2019

Copyright: Zhao et al. This is an open-access article distributed under the terms of the Creative Commons Attribution License 3.0 (CC BY 3.0), which permits unrestricted use, distribution, and reproduction in any medium, provided the original author and source are credited.

\section{ABSTRACT}

Abnormal FGFR1 alternative splicing is correlated with tumorigenicity and poor prognosis in several tumor types. We sought to determine the roles of FGFR1a and FGFR1 $\beta$ variants in breast cancer. TCGA samples and cell lines were analyzed for FGFR1a/FGFR1 $\beta$ expression. MCF-10A cells were used to overexpress these variants. Cell growth and transformation were assessed by SRB, colony formation, 3D-Matrigel, soft agar, cell motility assays. In TCGA, compared to FGFR1 non-amplified samples, FGFR1-amplified samples had significantly higher FGFR1a but not FGFR1 $\beta$ levels. FGFR1 $\beta$ expression levels and FGFR1ß/FGFR1a ratio were higher in basal subtype samples than in ER-positive/luminal samples in both TCGA and breast cancer cell lines. Both FGFR1a and FGFR1 $\beta$ induced transformation of MCF-10A cells. However, only FGFR1 $\beta$-expressing cells, not FGFR1a, enhanced cell growth and cell motility. Cells with higher FGFR1 $\beta$ levels and FGFR1 $\beta /$ FGFR1a ratio were more sensitive to FGFR inhibitor BGJ-398. Interestingly, in ER-negative cells, FGFR inhibitors decreased FGFR1 $\beta$ levels, likely by increasing expression of splicing repressor PTBP1. In ERpositive cells, estrogen treatment increased FGFR1 $\beta$ levels by decreasing PTBP1 expression, which was blocked by 4-OHT. Lastly, combination treatment with BGJ398 and 4-OHT synergistically inhibited cell survival. These findings suggest that FGFR1 alternative FGFR1a/FGFR1 $\beta$ splicing plays an important role in breast cancer.

\section{INTRODUCTION}

Breast cancer has high incidence and mortality rate and remains the second leading cause of cancer death in women world-wide $[1,2]$. The fibroblast growth factor receptor (FGFR) signaling pathway that regulates cancer cell growth and survival has been reported to play a crucial role in the development and progression of breast cancer [3, 4]. Deregulation of FGFR signaling by genetic alterations of FGFR1 has been found in breast cancer [5-7]. Amplification of FGFR1 located in chromosome $8 \mathrm{p} 11-12$ in $10-15 \%$ of breast cancer $[8,9]$, has been correlated with FGFR1 overexpression and poor overall survival, particularly in estrogen receptor-positive $\left(\mathrm{ER}^{+}\right)$ breast cancer [8-10]. Over the past years, alternative splicing events have been discovered in FGFR1 which 
were implicated in genesis and development of malignant tumors, including breast cancer $[6,11,12]$.

Extracellular region of FGFR1 comprises three Ig-like domains, IgI, IgII, and IgIII. Different from two proximal IgII and IgIII domains that determine ligand binding and specificity, the distal IgI and the following linker acid box $(\mathrm{AB})$ sequence are known to have an autoinhibitory function $[13,14]$. Alternative inclusion/exclusion of $\alpha$-exon (exon 3 ) that covers the IgI and AB linker region creates two splicing forms, FGFR $1 \alpha$ and FGFR $1 \beta$ respectively [15-17] (Supplementary Figure 1). This FGFR1 splicing event attracted attention during the past a couple of decades for their differential roles in cancer biology. FGFR1 $\beta$ was reported to have a higher binding affinity to FGF ligands than FGFR1 $\alpha[18,19]$. Several studies have implicated that overexpression of FGFR1 $\beta$ is associated with tumorigenesis and poor survival in multiple tumors [15, 17-19], while
FGFR $1 \alpha$, on the other hand, governs cell differentiation in normal tissues [15, 20, 21], suggesting that the two FGFR1 variants have different effects on cancer cells [19, 20].

In breast cancer, an early study reported that an increased FGFR $1 \beta$ and a decreased FGFR $1 \alpha$ expression correlated with reduced survival in breast cancer patients [22]. A recent preclinical study has revealed that FGFR1 $\beta$ promoted breast cancer metastasis while FGFR $1 \alpha$ had a suppressing function [23]. Together, these studies suggest that the differential FGFR1 alternative splicing events play an important role in breast cancer. However, given the limited experimental evidence so far, more comprehensive studies are necessary to establish pathophysiological role of alternative splicing of FGFR1 $\beta$ and FGFR1 $\alpha$ in governing tumor property of breast cancer and to provide novel therapeutic strategies. The current study was designed for this purpose.
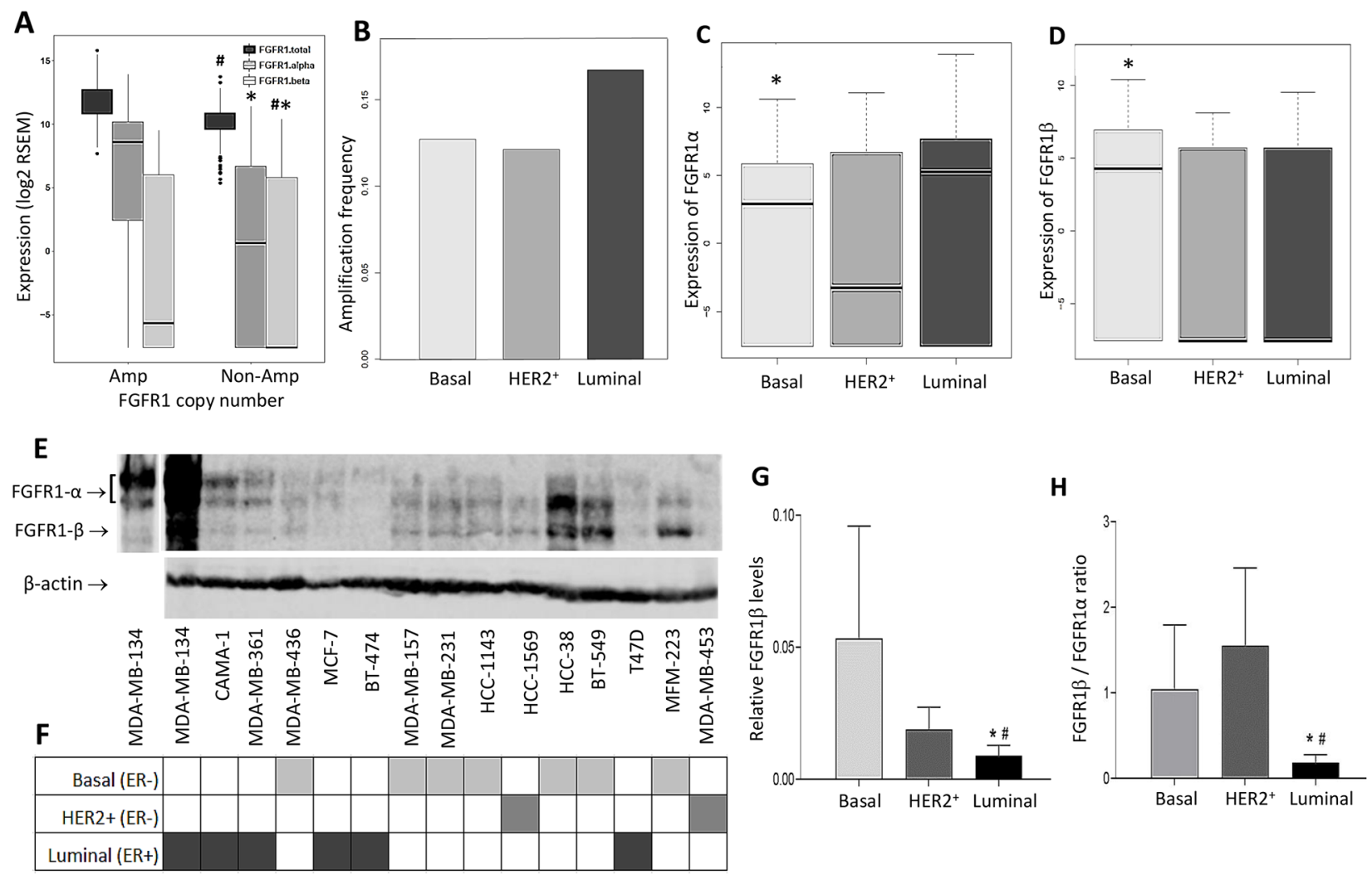

Figure 1: Differential expression of FGFR1 $\alpha$ and FGFR1 $\beta$ splicing variants in breast cancer patients and cell lines. (A-D) Bioinformatic analysis of expression of FGFR1 splicing variants in TCGA breast cancer samples. (A) Expression of FGFR1 variants in FGFR1-amplified and non-amplified samples. ${ }^{*}: \mathrm{p}=3.69 \mathrm{e}-19$ (amp vs non-amp); ${ }^{*}: \mathrm{p}=7.35 \mathrm{e}-15$ (amp vs non-amp); ${ }^{* *}$ : $\mathrm{p}=0.721$ (amp vs non-amp). (B) FGFR1 amplification frequency in subtypes. FGFR1 copy numbers were analyzed for amplification frequency in 3 groups of samples - basal, HER2+ and luminal subtypes. (C) Expression of FGFR1 $\alpha$ in 3 subtype groups. *: $p=0.0305$ (basal vs luminal). HER2 ${ }^{+}$ vs luminal: $p=0.105$; basal vs HER2 ${ }^{+}: p=0.669$. (D) Expression of FGFR1 $\beta$ in 3 subtype groups. * : $p=0.0016$ (basal vs luminal). HER2 ${ }^{+}$vs luminal: $p=0.812$; basal vs HER2 ${ }^{+}: p=0.0725$. (E) Immunoblotting of FGFR1 in the cell lines. Cell lysates were prepared from 15 breast cancer cell lines and analyzed by SDS-PAGE. FGFR $1 \alpha$ and FGFR1 $\beta$ proteins were detected by anti-FGFR1 antibody. The first lane on the left was the same lane of MDA-MB-134VI cells with lighter exposure. (F) Subtypes of breast cancer cell lines. (G) RelativeFGFR1 $\beta$ levels in cell lines. The relative FGFR1 $\beta$ levels were obtained by normalizing with $\beta$-actin. ${ }^{*}: \mathrm{p}=0.0065$ (basal vs luminal); \#: $\mathrm{p}=0.0003$ (HER2 ${ }^{+}$ vs luminal). (H) FGFR1 $\beta$ /FGFR1 $\alpha$ ratio in cell lines. FGFR1 $\beta$ and FGFR1 $\alpha$ expression levels in WB were quantitated by ImageJ software. The FGFR1- $\beta$ /FGFR1 $\alpha$ ratio was present in each subtype groups. ${ }^{*}$ : $\mathrm{p}<0.01$ (basal vs luminal); \#: $\mathrm{p}<0.001$ (HER2 ${ }^{+}$vs luminal). 


\section{RESULTS}

\section{Differential expression of FGFR1 splicing variants in breast cancer}

We analyzed the TCGA database of breast cancer patients and compared expression levels of alternatively spliced FGFR $1 \alpha$ and FGFR1 $\beta$ in different breast cancer subtypes. Relative FGFR $1 \alpha$ and FGFR $1 \beta$ expression levels were represented by their mRNA expression levels (log2 RSEM) from normalized read counts. First we determined whether both isoforms were overexpressed in patients with FGFR1 amplification. We found that FGFR1 $\alpha$ expression levels were significantly higher in FGFR1-amplified samples than that in non-amplified samples (median level 8.6 vs $0.66, \mathrm{p}=3.69 \mathrm{e}-19$ ) (Figure 1A). On the other hand, FGFR1 $\beta$ expression did not exhibit a significant difference between the groups, although its median level was slightly higher in FGFR1-amplified samples compared to nonamplified samples (-5.63 vs -7.56) (Figure 1A). Thus there was a higher FGFR1//FGFR1 $\alpha$ ratio in FGFR1non-amp samples compared to amplified samples. Next, we examined the expression of FGFR1 isoforms in three breast cancer subtypes. We found that $\mathrm{ER}^{+}$luminal samples had higher FGFR1 amplification frequency than basal and HER2 ${ }^{+}$subtypes (Figure 1B). Interestingly, FGFR1 $\alpha$ levels in luminal samples were significantly higher than that in basal subtype samples (median levels 5.29 vs 2.93 , $\mathrm{p}=0.0305$ ) (Figure 1C). In contrast, FGFR1 $\beta$ levels were substantially lower in luminal samples than that in basal samples (median levels -7.56 vs 4.27, $\mathrm{p}=0.0016$ ) (Figure 1D). No significant differences for expression of either FGFR $1 \alpha$ or FGFR $1 \beta$ were detected between luminal and HER 2+ and between basal and HER 2+ groups (Figure 1C, 1D). The differential expression of these variants leads to a greater FGFR1 $\beta /$ FGFR $1 \alpha$ ratio in basal samples than that in luminal samples ( $\mathrm{p}=1.14 \mathrm{e}-05)$ (Supplementary Figure 2).

Next, we examined differential expression of FGFR1 splicing variants in breast cancer cell lines. Immunoblot screening of a panel of 15 breast cancer cell lines showed that relative FGFR $1 \beta$ levels were significantly greater in ER' cell lines, particularly in basal subtype, than those in $\mathrm{ER}^{+}$luminal subtype cell lines (Figure 1E-1G, Supplementary Figure 3), which resulted in a consequent higher FGFR1//FGFR1 $\alpha$ ratio in ER' cell lines than in $\mathrm{ER}^{+}$cell lines (Figure 1H). This overall cell line pattern is consistent with the finding in the TCGA patient samples.

\section{Influence of FGFR1 variants on FGFR signaling and cell proliferation}

FGFR1 alternative splicing isoforms FGFR $1 \alpha$ and FGFR1 $\beta$ have been found to differ in ligand binding. Specifically, FGFR1 $\beta$ has higher binding affinity to FGFs than FGFR $1 \alpha$, and this has been proposed to give rise to more FGF signaling activity in the cells $[16,18,19]$. To evaluate the role of these FGFR1 variants in regulation of FGFR signaling activity, we overexpressed FGFR $1 \alpha$ and FGFR1 $\beta$ in MCF-10A cells (Figure 2A). These mammary epithelial cells are known not to express FGFR1 proteins [23]. We analyzed the influence of the FGFR1 isoforms on signaling activities of both MAPK and PI3K pathways. In the MAPK pathway, immunoblotting showed that basal levels of both phospho-MEK1/2 and phospho-ERK1/2 in FGFR1 $\beta$-bearing cells are substantially elevated above the levels in control cells (Figure 2B). Differently, overexpression of FGFR $1 \alpha$ in contrast slightly decreased basal phospho-ERK1/2 levels but mildly increased phospho-MEK1/2 production (Figure 2B). However, there appeared to be no significant difference in response to FGF2 enhancement of signaling activity between all these MCF-10A cells (Figure 2B). In the PI3K pathway, we found that overexpression of FGFR1 $\beta$ increased phospho-S6 in both absence and presence of FGF2, compared to control and FGFR1 $\alpha$-expressing cells (Figure 2C). However, we could not detect changes in phosphoAKT levels between the groups (Figure 2C). FGF2 increased phospho-S6 levels in all three cell lines, without increasing Akt phosphorylation.

Activation of FGFR1 signaling is known to promote cell proliferation. To examine if FGFR $1 \alpha$ and FGFR $1 \beta$ play differential roles in cell proliferation, we performed cell SRB growth rate assay. The results showed that overexpression of FGFR $1 \alpha$ slightly stimulated cell growth compared to empty vector controls over the time course. But, the MCF-10A cells expressing FGFR1 $\beta$ variant had significantly greater cell growth rate (Figure 2D). To further confirm the effects of FGFR1 variants on cell growth, we assessed colony formation capability of these cells. Similarly, we found that while FGFR1 $\alpha$ was able to mildly increase colony formation, FGFR1 $\beta$-expressing cells exhibited significantly enhanced colony formation capability in comparison with vector controls (Figure 2E). Total colony area and average colony size in FGFR1 $\beta$ expressing cells were about 2-and 3-fold larger over the control cells (Figure 2F, 2G).

\section{Influence of FGFR1 variants on cell transformation}

Non-transformed MCF-10A mammary epithelial cells are capable of forming growth-arrested acini-like spheroid architecture on an anchorage independent growth model $[24,25]$. To assess the influence of FGFR1 variants on acinar morphology, a three dimensional culture was performed in the presence or absence of FGF2, or BGJ398 for 3 weeks. Phase-contrast micrograph showed that in the vehicle groups, the control MCF-10A cells processed normal spherical acini-like structure on the 3D-Matrigel. However, expression of FGFR $1 \alpha$ and FGFR $1 \beta$ variants disrupted this morphogenetic process, eliciting distinct 
morphological phenotypes. Both FGFR $1 \alpha$ - and FGFR1 $\beta$ bearing cells formed irregular acinar morphology with abnormal invading protrusions. In some cells, spiculate structures were also observed (Figure 3A). Addition of FGF2 to the culture increased acini size in all three groups, and produced robust and complex multi-acinar structures particularly in FGFR $1 \alpha$-bearing cells, (Figure 3A). FGFR inhibitor treatment appeared not to restore these morphological changes (Figure 3A). In another anchorage independent growth assay, we found that after a three-week culture in soft agar, both MCF-10A-FGFR $1 \alpha$ and MCF-10A-FGFR1 $\beta$ cells formed robust colonies, compared to the control MCF-10A cells which formed much smaller colonies in soft agar (Figure 3B).

MCF-10A cells express E-cadherin that plays a principal role in maintaining normal mammary epithelial cell morphology. Disruption of E-cadherin junctions and consequent gain of cell motility contribute to epithelial-tomesenchymal transition (EMT) $[26,27]$. Previous studies demonstrated that TGF- $\beta 1$ induces EMT of MCF-10A cells by reducing E-cadherin expression [27, 28]. Here, we examined the involvement of FGFR1 splicing variants in this pathological process. Immunoblotting results revealed that overexpression of either FGFR $1 \alpha$ or FGFR $1 \beta$ in MCF-10A cells decreased E-cadherin expression and robustly synergized with TGF- $\beta 1$ treatment to reduce E-cadherin levels (Figure $3 \mathrm{C}$ ). These results indicate that both FGFR $1 \alpha$ and FGFR1 $\beta$ are capable of inducing cell transformation.

\section{Influence of FGFR1 variants on cell motility}

Enhanced migration and invasion capabilities are two critical features of transformed tumor cells. Here, we investigated the role of FGFR1 alternative splicing in these pathological events. In wound healing assay, we found that overexpression of FGFR $1 \alpha$ did not affect cell migration, compared to control MCF-10A cells, but the FGFR1 $\beta$ bearing cells migrated vigorously from the edges of wound scratch, leading to almost closure of wound scratch gap, as
A

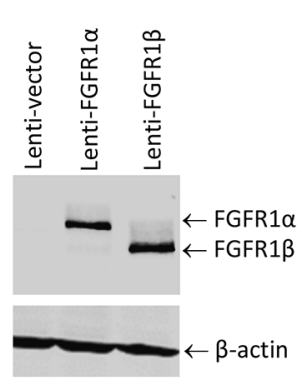

B

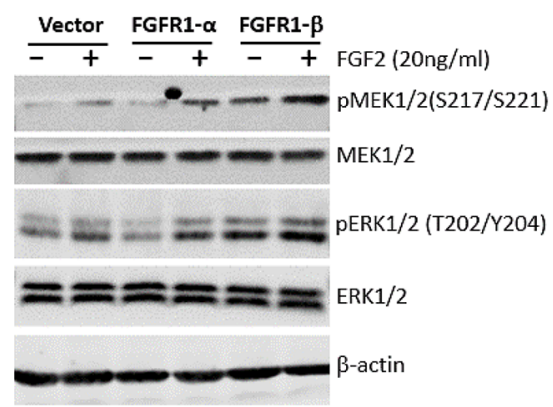

C

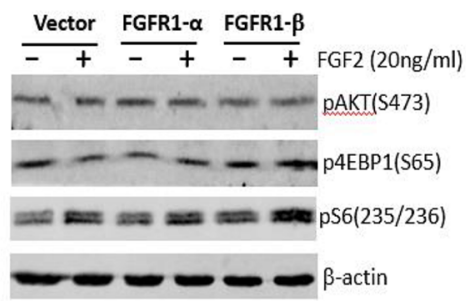

D

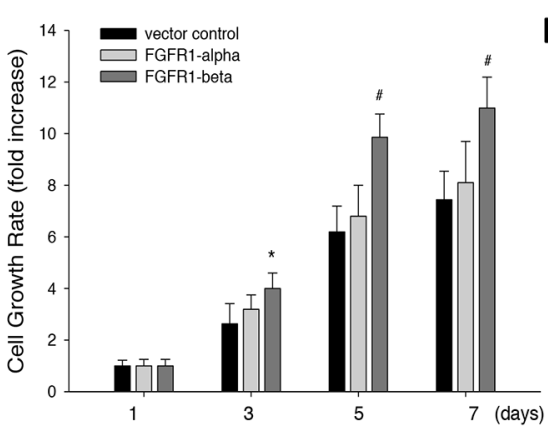

E

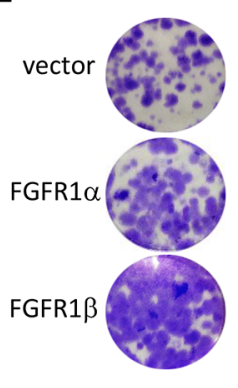

$\mathbf{F}$

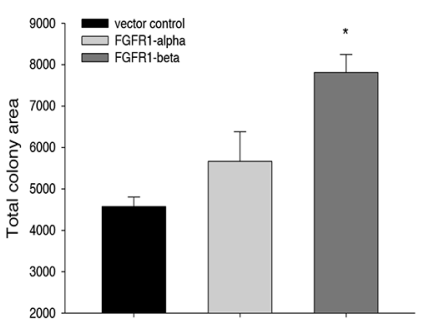

G

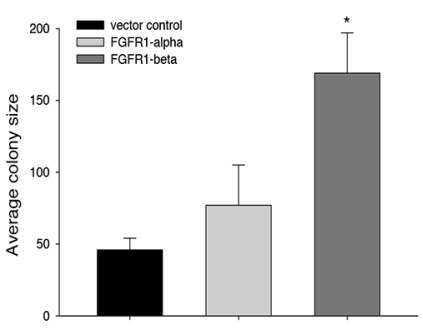

Figure 2: Effects of overexpression of FGFR1 $\alpha$ and FGFR1 $\beta$ in MCF-10A cells on FGFR signaling and cell proliferation. (A) Viral FGFR1 expression. Virus particles were packaged for FGFR1 $\alpha$ and FGFR1 $\beta$, and were infected into MCF-10A cells. Expression of FGFR1 was confirmed by immunoblotting with anti-FGFR1 antibody. (B, C) Immunoblotting of FGFR signaling activity. MCF10Acells were treated with FGF2 at $20 \mathrm{ng} / \mathrm{ml}$ or vehicle control for 24 hours. The MAPK pathway was detected in the cell lysates with antibodies against phospho-MEK1/2, phospho-ERK1/2 (B), while the PI3K pathway was detected with antibodies against phospho-pAKT, phospho-S6 and phospho-4E-BP1 (C). (D) Cell growth rate. MCF-10A cells expressing FGFR1 $\alpha$, FGFR1 $\beta$, and vector were cultured in 96well plates in a normal condition for the indicated days. Cell viability was measured by SRB staining. Cell proliferation rate was calculated by normalizing OD490nm values to day 1 OD value. ${ }^{\#}: \mathrm{p}<0.05$ vs empty vector; ${ }^{*}: \mathrm{p}<0.01$ vs empty vector. (E-G) Cell colony formation. MCF-10A cells seeded in 6-well plates were cultured for 3 weeks followed by crystal violet staining (E). Total colony area (F) and average colony size $(\mathrm{G})$ were quantitated using ImageJ software. Average values were calculated from triplicate wells for each group. *: $\mathrm{p}<0.01 \mathrm{vs}$ empty vector. 
measured by relative fractions of wound gap (Figure 4A, 4B). Addition of FGFR inhibitor BGJ-398 inhibited cell motility in all three cell groups (Figure 4A, 4B).

We also examined the cell invading ability which is an initial metastatic process of tumor cells to pass enzymatically through the dense surrounding extracellularmatrix of basement membranes and stromal compartments, using a transwell invasion assay. Starved MCF-10A cells were seeded onto the transwells coated with BME and allowed to invade through the BME towards the attraction of serum-containing medium. Staining of the cells that invaded through the BME membrane showed that the cells overexpressing FGFR1 $\beta$, but not FGFR1 $\alpha$, displayed a higher invading ability than the control cells (Figure $4 C)$. The quantitation of invaded cell number indicated that FGFR1 $\beta$, but not FGFR1 $\alpha$, significantly enhanced invasion capability of the transformed MCF-10A cells (Figure 4D).

\section{Influence of FGFR1 variants on downstream functional pathways}

We also evaluated the impact of differential levels of FGFR $1 \alpha$ and FGFR $1 \beta$ on gene expression of downstream signaling pathways using the same TCGA data. First, we looked at FGFR $1 \alpha$ and FGFR1 $\beta$ expressing and nonexpressing samples. Out of 18,319 qualified genes, 1512 and 1577 differently expressed genes (DEGs) with FDR (false discovery rate) 0.001 and fold changes larger than 2 were identified to be associated with the differential expression of FGFR $1 \alpha$ and FGFR $1 \beta$ respectively (Supplementary Figure 4A,B,G). We also analyzed the samples with differential FGFR $1 \beta /$ FGFR $1 \alpha$ ratio. The results of top $10 \%$ and bottom $10 \%$ FGFR $1 \beta /$ FGFR $1 \alpha$ ratio samples showed that among 17,541 qualified genes, 1,777 DEGs were identified to be strongly associated with FGFR $1 \beta /$ FGFR $1 \alpha$ ratio (Supplementary Figure $4 C, G)$. In the hierarchically clustered heatmap of DEGs, high FGFR1 $\beta /$ FGFR $1 \alpha$ ratio samples and low FGFR $1 \beta$ / FGFR $1 \alpha$ ratio samples showed a more distinguishing pattern on separation of DEGs, compared to those for FGFR $1 \alpha$ and FGFR $1 \beta$ expressing and non-expressing samples (Supplementary Figure 4A-C). These results indicate that high and low FGFR $1 \alpha$ and FGFR $1 \beta$ levels, in particular, high and low FGFR $1 \beta /$ FGFR $1 \alpha$ ratios have a largely opposite effects on switching on/off expression of these downstream genes, which may contribute to their divergent tumorigenic function. Furthermore, using

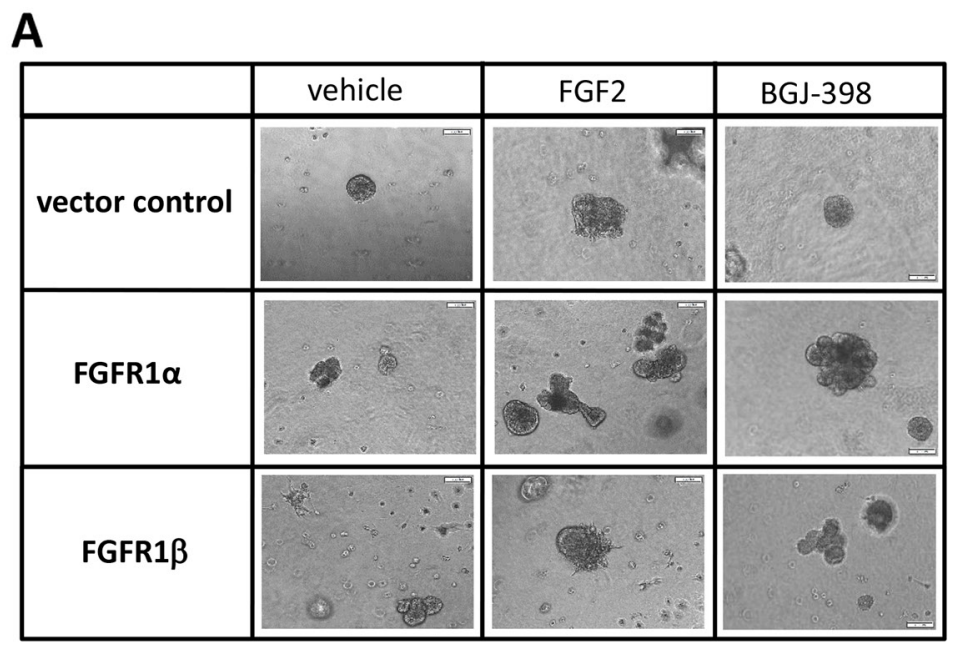

B

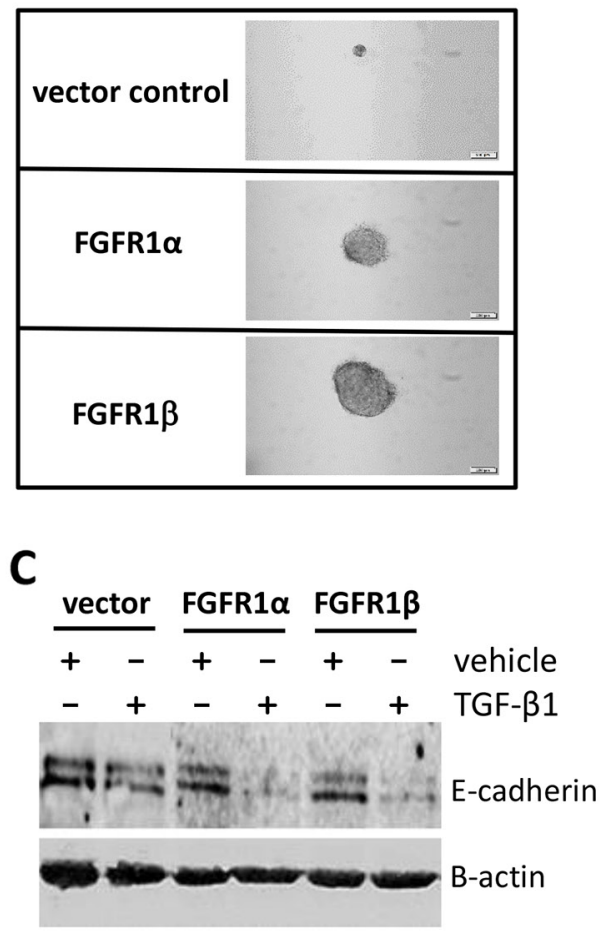

Figure 3: Effects of overexpression of FGFR1 $\alpha$ and FGFR1及 on cell transformation. (A) Three-dimensional Matrigel assay. MCF-10A cells expressing FGFR1 $\alpha$, FGFR1 $\beta$, and vector were seeded into chamber wells coated with Matrigel in MEGM medium containing FGF2 at $20 \mathrm{ng} / \mathrm{ml}$ and BGJ-398 at $2 \mu \mathrm{M}$ for 3 weeks. Phase-contrast micrographs of spherical mammary structure were captured. (B) Soft agar assay. MCF-10A cells were seeded into 3.5\% agar gel and cultured for 3 weeks. Anchorage-independent colonies were visualized by Iodonitrotetrazolium chloride staining. (C) E-cadherin immunoblotting. MCF-10A cells were treated with TGF- $\beta 1$ at $5 \mathrm{ng} / \mathrm{ml}$ or vehicle control for 2 days. Cell lysates were analyzed by western blot using anti-E-cadherin antibody with a normalization by $\beta$-actin. 
Ingenuity Pathway Analysis (IPA) bioinformatics software we performed signaling pathway analysis and identified top 10 canonical pathways for each of DEG analyses (Supplementary Figure 4D-F).

\section{Influence of FGFR1 variants on cell sensitivity to FGFR inhibitor}

We sought to answer if differential expression of FGFR1 isoforms impacts cell response to FGFR inhibitors. Thus, we screened the panel of 15 breast cancer cell lines that differentially expressed FGFR $1 \alpha$ and FGFR1 $\beta$ variants as described in Figure 1E-H for their response to BGJ-398 treatment. The differential FGFR1 $\beta$ expression levels and FGFR1 $\beta / F G F R 1 \alpha$ ratio in these cell lines were displayed in Figure 5B,C. Cell survival assay showed that these cell lines had varying sensitivities to the FGFR inhibitor with IC50s ranging from about 0.3 $10 \mu \mathrm{M}$ (Figure 5A). Pearson correlation analysis showed that the cell line sensitivity to the FGFR inhibitor was significantly correlated with both FGFR1 $\beta$ levels and FGFR1 $\beta$ /FGFR $1 \alpha$ ratio (Figure 5E, 5F). Cells that express high FGFR1 $\beta$ levels and high FGFR $1 \beta /$ FGFR $1 \alpha$ ratio were more sensitive to the FGFR inhibitor than the cells with low levels and low ratio (Figure 5D).

We wondered whether FGFR inhibition has an impact on FGFR1 splicing. Surprisingly we found that treatments with FGFR inhibitors BGJ-398 and Debio-1347 were capable of decreasing FGFR1 $\beta$ levels in ER ${ }^{-}$MFM223 cells compared to the vehicle treatment (Figure $5 \mathrm{G})$, suggesting that the growth inhibitory effect of the FGFR inhibitors not only results from direct inhibition of FGFR signaling, but may be also a consequence of indirect inhibition of FGFR1 $\beta$ expression. In exploring the potential mechanisms involved in regulation of FGFR1 alternative splicing by FGFR inhibitors, polypyrimidine tract-binding protein 1 (PTBP1) has emerged as a protein of interest, as it is known as a splicing repressor [29-31]. When MFM-223 cells were treated with these FGFR inhibitors for 3 days, they expressed higher levels of

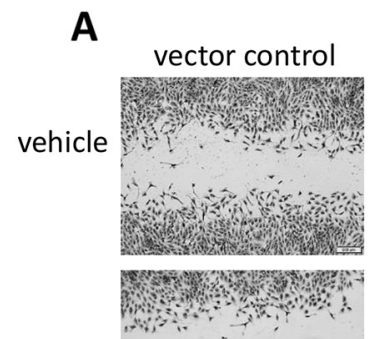

BGJ-398
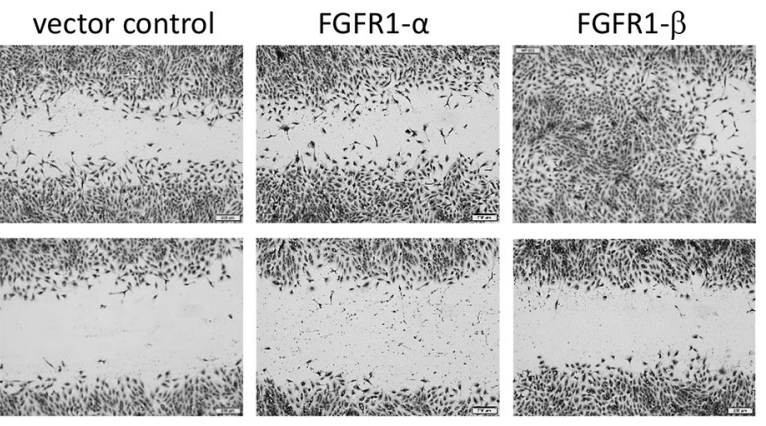

B
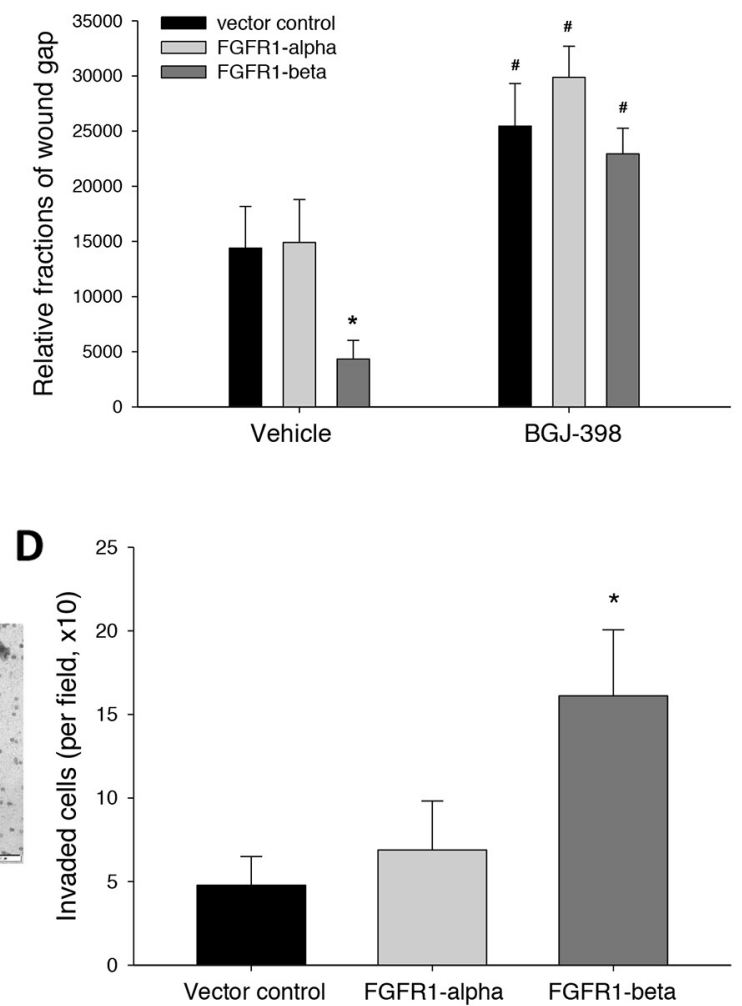

Figure 4: Effects of overexpression of FGFR1 $\alpha$ and FGFR1ß on cell migration and invasion capability. (A, B) Wound healing assay. Wound scratches were made on the confluent MCF-10A cells in 12-well plates. Following 2-day culture with BGJ-398 at $2 \mu \mathrm{M}$ or vehicle control for 2 days, followed by crystal violet. Wound gap images were captured (A). Relative wound gap areas were quantitated using ImageJ software (B) *: $\mathrm{p}<0.01$ vs empty vector; \#: $\mathrm{p}<0.01$ vs vehicle control. (C, D) Transwell matrigel invasion assay. Starved MCF$10 \mathrm{~A}$ cells were seeded with serum-free medium into transwells coated with basement membrane extract (BME). The transwell inserts were assembled into 24 -well plates with $10 \%$ FBS medium and cultured for 24 hours. The cells that invaded through the BME were fixed and stained with crystal violet (C). Images of the cells on the membrane were taken. Cell numbers were counted per field (D). *: p $<0.001$ vs vector control. 

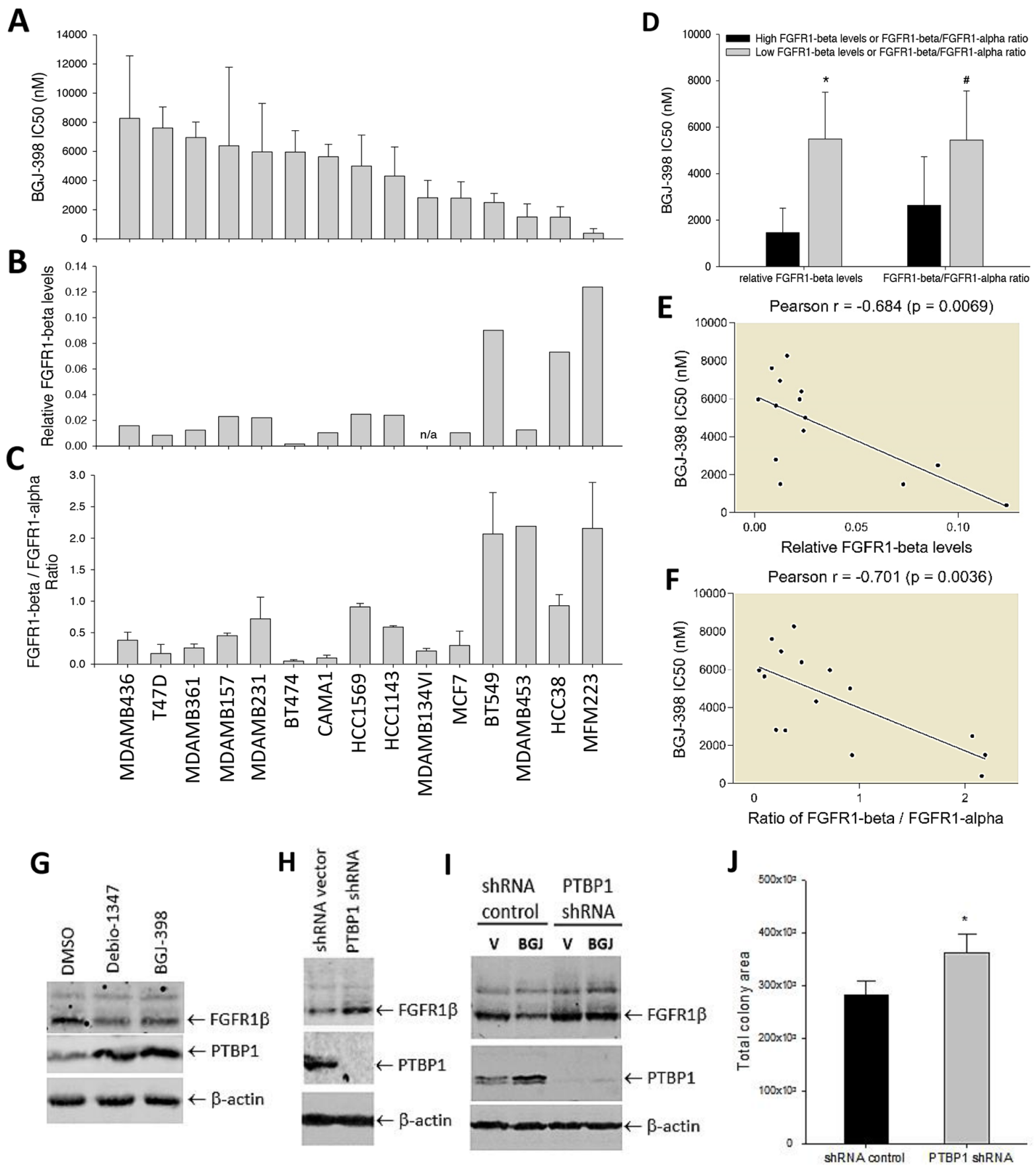

Figure 5: Effects of FGFR1 $\alpha$ and FGFR1ß on cell sensitivity to FGFR inhibitors on cell survival. (A) Cell survival screening. Cell lines seeded in 96-well plates were incubated with BGJ-398 at a serial dilutions for 3 days, followed cell viability measurement by SRB. IC50s of cell survival inhibition were calculated using GraphPad Prism7 software. (B) FGFR1 $\beta$ levels in cell lines measured by WB in Figure 1C. (C) FGFR1//FGFR1 $\alpha$ expression ratio in the cell lines measured by WB in Figure 1C. (D) BGJ398 IC50s in cell line groups with high and low FGFR1 $\beta$ levels and FGFR1 $\beta$ FGFR1 $\alpha$ ratio with thresholds 0.05 and 0.9 respectively. ${ }^{*}: \mathrm{p}=0.015$; $\#$ : $\mathrm{p}=0.0033$ (low vs high). (E, F) Correlations between BGJ-398 IC50 and absolute FGFR1 $\beta$ levels (E) or FGFR1 $\beta / F G F R 1 \alpha$ ratio (F). The correlation analysis for Pearson $r$ value was performed using GraphPad Prizm7 software. (G) MFM-223 cells were treated with Debio-1347 or BGJ-398 at $2 \mathrm{uM}$ for 3 days. Expression of FGFR1 and PTBP1 were detected by immunoblotting with anti-FGFR1 and anti-PTBP1 antibodies. (H) PTBP1 knockdown. MFM-223 cells were infected with PTBP1 shRNA virus or control shRNA vector. FGFR1 and PTBP1 were detected by immunoblotting. (I) PTBP1-deficient cells and control shRNA cells were incubated with BGJ-398 at 2uM or vehicle controls for 3 days, followed by immunoblotting. (J) Colony formation of PTBP1-deficient cells. The control and PTBP1-knockdown MFM-223 cells were cultured for 3 weeks for colony formation. Total colony area was quantitated by ImageJ. *: $\mathrm{p}=0.0136$. 
PTBP1 than controls (Figure 5G). This action was further confirmed by a knockdown study. We found that in the cells, where the PTBP1 was completely depleted, there was a substantial increase in FGFR $1 \beta$ levels compared to shRNA controls (Figure 5H). Furthermore, we found that PTBP1 loss-of-function clearly removed the effect of BGJ-398 on decreasing FGFR1 $\beta$ expression (Figure 5I). To provide more supporting evidence, we performed chromatin immunoprecipitation (ChIP) assay. The data showed that the splicing regulator PTBP1 bound to one of two specific intronic slicing sequences (ISS) flanking the " $\alpha$ exon" region of the FGFR1 gene in MFM-223 cells (Supplementary Figure 5). PTBP1 deficiency reduced the binding in the cells (Supplementary Figure 5). Functionally, colony formation assay showed that PTBP1 depletion promoted cell growth in these cells (Figure 5J). These results suggest that the FGFR inhibitor downregulates FGFR1 $\beta$ production by upregulating expression of splicing repressor PTBP1 in the cells.

\section{Estrogen regulation of FGFR1 splicing in breast cancer cells}

ER activation is reported to regulate alternative splicing of FGFR2 [32]. Therefore, we were interested in inspecting estrogen regulation of FGFR1 splicing and its consequence in breast cancer cells. First, we examined the expression of FGFR $1 \alpha$ and FGFR $1 \beta$ in $\mathrm{ER}^{+}$ MDA-MB-134VI cells under the influence of estrogen and its antagonist. RT-PCR results showed that when MDA-MB-134VI cells were exposed to $17-\beta$-estradiol at $0.1 \mu \mathrm{M}$ in a hormone-deprived condition for 2 days, FGFR $1 \alpha$ levels were reduced, along with an increase in FGFR1 $\beta$ levels, compared to the vehicle controls (Figure 6A). In contrast, the cells treated with estrogen inhibitor 4-hydroxytamoxifen (4-OHT, the active metabolite of tamoxifen) at $1 \mu \mathrm{M}$ produced less FGFR $1 \alpha$ but more FGFR1 $\beta$ variants compared to the controls (Figure 6A). In addition, 4-OHT was also capable of blocking the estrogen-induced changes in alternative FGFR1 splicing (Figure 6A). Consistently, immunoblotting and its quantitation showed that $17-\beta$-estradiol and 4-OHT dosedependently increased or decreased FGFR $1 \beta /$ FGFR $1 \alpha$ ratio respectively in these cells (Figure 6B, 6C). In contrast to FGFR inhibitor, we noticed that $17-\beta$-estradiol treatment clearly reduced PTBP1 levels in MDA-MB134VI cells, leading to an increase in FGFR1 $\beta$, compared to vehicle controls (Figure 6D). Similarly, PTBP1 deficiency by shRNA in MDA-MB-134VI cells increased FGFR1 $\beta$ levels (Figure 6D). These results suggest that, in contrast to FGFR inhibitor, activation of ER signaling enhances FGFR1 $\beta$ alternative splicing by inhibiting PTBP1 expression in $\mathrm{ER}^{+}$cells.

Given the fact that both ER and FGFR signaling are involved in regulation of FGFR $1 \beta$ splicing via PTBP1, we determined whether there is a synergy between ER and FGFR inhibition on cell survival. First, we found that $17-\beta$-estradiol at $0.1 \mu \mathrm{M}$ increased growth rate of $\mathrm{ER}^{+}$ MDA-MB-134VI cells in a time course, while it did not affect ER- MFM-223 cells (Supplementary Figure 6A, $6 \mathrm{~B})$. In drug combination study on MDA-MB-134VII cells, we found that co-treatment with ER-antagonist 4-OHT and FGFR inhibitor BGJ-398 substantially reduced IC50s of each drug, compared to the IC50s of single drug treatment, leading to a synergy on cell growth inhibition with a combination index 0.651 (Figure 6E). This synergy was also seen in colony formation assay of MDA-MB-134VI cells where colony formation inhibition was synergistically enhanced by combining BGJ-398 and 4-OHT with a CI 0.78 (Figure 6F). Synergy between 4-OHT and BGJ-398 was also seen in other $\mathrm{ER}^{+}$cells, such as CAMA-1 cells (Supplementary Figure 7A). However, we did not identify synergistic effects between fulvestrant and BGJ-398 (Supplementary Figure 7B, 7C). On the other hand, we also could not detect synergy in ER- breast cancer cells, MFM-223 cells.

\section{DISCUSSION}

Breast cancer has three intrinsic subtypes, basal, HER $2^{+}$, and luminal, based on their gene expression profiles [33]. Results from our bioinformatics analysis of breast cancer patient samples and breast cancer cell line study revealed that FGFR $1 \alpha$ and FGFR $1 \beta$ expression have distinct distributions across different groups, including FGFR1-amplified and non-amplified groups, and three subtype groups. In brief, FGFR1-amplified samples have significantly higher FGFR1 $\alpha$ expression compared to non-amplified samples, while FGFR $\beta$ is not significantly higher. We found that patients with basal tumors express higher FGFR1 $\beta$ levels than luminal breast cancer patients (Figure 1D), which is consistent with the finding from cell lines where FGFR1 $\beta$ levels are higher in basal subtype cell lines than other two subtypes (Figure $1 \mathrm{G}$ ). However, we could not identify significant differences in FGFR $1 \alpha$ and FGFR1 $\beta$ levels between luminal and HER2+ subtypes. This phenomenon may at least in part explain the pathological changes in basal subtype which accounts for up to $90 \%$ triple negative breast cancer (TNBC), different from the other two subtypes. Our data suggest that high expression of FGFR $1 \beta$ could be one of crucial risk factors that confer aggressive pathology feature and poor prognosis in basal breast cancer.

Early studies in other tumors have implicated that FGFR1 $\beta$, but not FGFR1 $\alpha$, plays a pivotal role in tumorigenesis, such as in glioblastoma, astrocytoma, acute myeloid leukemia, and bladder tumor [15, 1719]. However, in the present study using a mammary epithelial cell model, we found that overexpression of either FGFR $1 \beta$ or FGFR1 $\alpha$ in MCF-10A cells is capable of inducing tumorigenic transformation of these normal mammary epithelial cells, as evidenced by formation of 
irregular spheroid structure in 3D culture and enhanced anchorage independent growth in soft agar. Previous studies found that TGF- $\beta$ induces epithelial-mesenchymal transition (EMT) of non-malignant epithelial MCF-10A cells by downregulating E-cadherin downregulation $[27,28]$. Interestingly, we found that both FGFR $1 \beta$ and FGFR $1 \alpha$ synergize with TGF- $\beta$-mediated reduction of E-cadherin. This may partially explain why both FGFR $1 \beta$ and FGFR $1 \alpha$ similarly induce transformation of mammary epithelial cells. Nevertheless, the basis for the observed differential roles of FGFR $1 \alpha$ in tumorigenesis and tumor malignancy between breast cancer and other tumors needs further investigation.

FGFR1 is not only considered important for breast cancer tumorigenesis, but it also has been recently discovered to promote breast cancer metastasis. FGFR1 amplification is more commonly seen in invasive breast carcinoma tissue than in the ductal carcinoma in situ (DCIS) [34]. In a knockout mouse model, Wang et al demonstrated that deletion of FGFR1 in mammary tumors greatly reduced tumor metastasis to the lung [35]. Here, we found through in vitro invasion and migration assays that FGFR1 $\beta$, but not FGFR1 $\alpha$, is a dominant FGFR1 isoform that boosts motility of transformed breast cells. This finding is consistent with the phenomenon in Wendth's in vivo mouse model where FGFR1 $\beta$ proved to be required for pulmonary outgrowth of metastatic breast cancer [23].

Abnormal FGFR activity can drive tumorigenesis. Our results demonstrate that FGFR1 alternative splicing variants FGFR $1 \alpha$ and FGFR $1 \beta$ function differently in breast cancer. Thus, we wanted to explore the potential mechanisms underlying such distinctive functions. Among a number of identified DEGs associated with FGFR $1 \alpha$ and FGFR $1 \beta$ expression levels or FGFR1 $\beta$ / FGFR $1 \alpha$ ratio, some are overlapped between these DEG analyses (Supplementary Excel file: DEG FDR0.001). Moreover, IPA assay showed that a number of potential pathways may be involved in these phenotypes, where some pathways are found overlapped (Supplementary
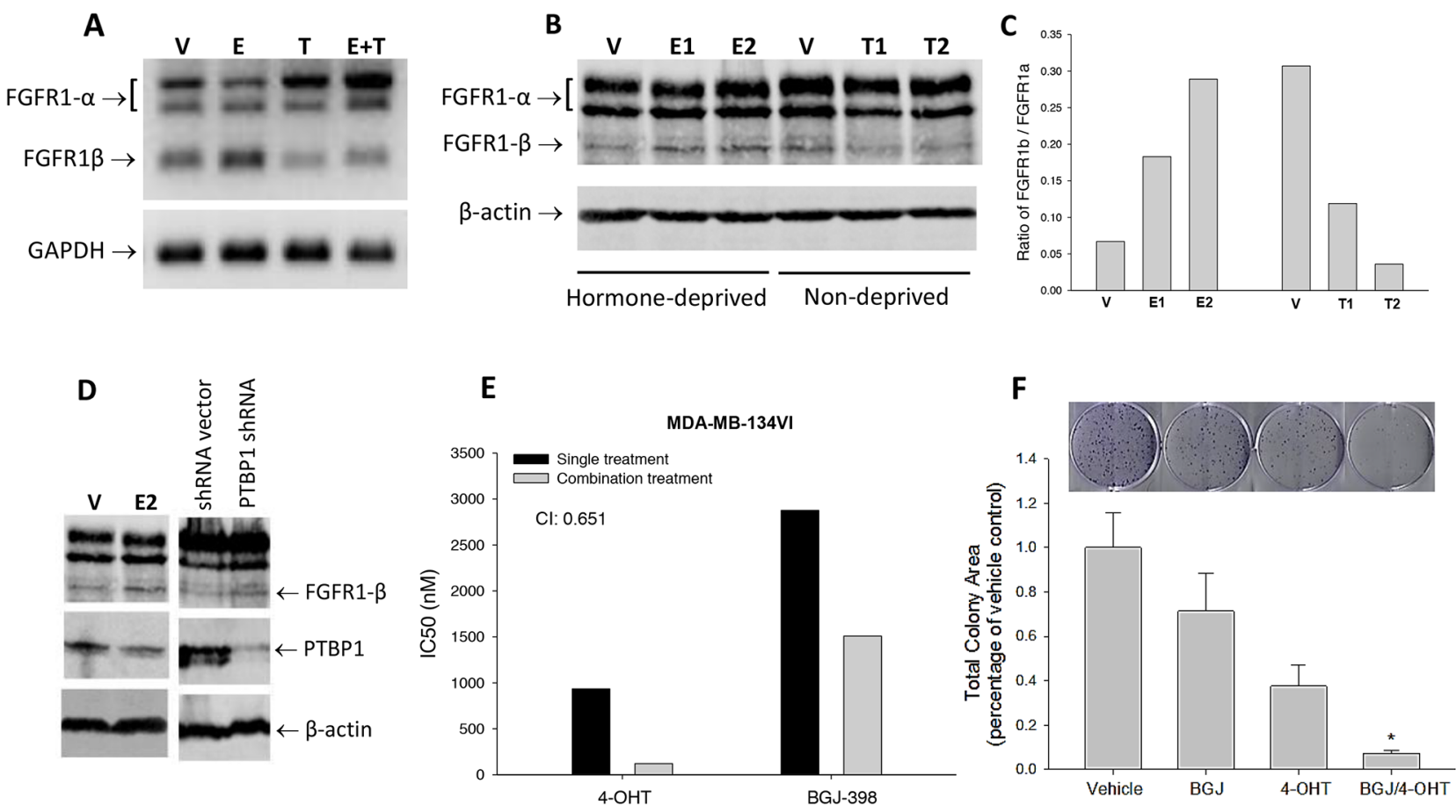

Figure 6: Estrogen regulation of FGFR1 splicing in breast cancer cells. (A) RT-PCR of FGFR1 $\alpha$ and FGFR1 $\beta$. MDA-MB-134VI cells were cultured for 3 days with hormone-deprived FBS, then treated with $17 \beta$-estradiol at $0.1 \mu \mathrm{M}(\mathrm{E}), 4$-hydroxytamoxifen at $1 \mu \mathrm{M}(\mathrm{T})$, or both (E+T), or vehicle (V) for 2 days. RT-PCR was performed to detect mRNAs of FGFR1 $\alpha$, FGFR1 $\beta$, and GAPDH. (B) Immunoblotting. The MDA-MB-134VI cells cultured with hormone-deprived FBS or normal FBS for 3 days were incubated with 17 $\beta$-estradiol or 4-hydroxytamoxifen treatment respectively for 2 days. E1 and E2: $17 \beta$-estradiol at 0.1 and $0.5 \mu \mathrm{M}$; T1 and T2: 4-hydroxytamoxifen at 1 and $5 \mu \mathrm{M}$; V: vehicle. (C) Ratio of quantitated FGFR1 $\beta$ /FGFR1 $\alpha$ expression in Figure 6B. (D) WB of FGFR1 and PTBP1. MDA-MB$134 \mathrm{VI}$ cells were treated with $17 \beta$-estradiol (E2) at $0.1 \mu \mathrm{M}$ or vehicle control for 2 days, or infected with PTBP1 shRNA virus or control shRNA. Expression of FGFR1 and PTBP1 were detected with anti-FGFR1 and anti-PTBP1 antibodies. (E) Effects of drug combination on cell survival. MDA-MB-134VI cells seeded in 96-well plates were incubated with single or combination of 4-hydroxytamoxifen and BGJ-398 at doses from $0.05-20000 \mathrm{nM}$ and 1250-20000nM respectively for 5 days. Cell survival rate was measured by SRB assay. IC50 and combination index (CI) were calculated using CompuSyn software. (CI $<1$ : synergy; $\mathrm{CI}>1$ : antagonism) (F) Colony formation assay. MDA-MB-134VI cells were cultured in the presence of BGJ-398 and 4-OHT at 1nM and 0.1nM respectively and their combination for 4 weeks. Colony formation was visualized by crystal violet staining. Total colony area was quantitated using ImageJ. 
PDF file: IPA Pathways). These results may provide speculations to further pursuit the precise molecular mechanisms responsible for the role of FGFR1 splicing in breast cancer.

FGFR signaling is frequently deregulated in many cancers, including breast cancer, playing a role in the pathogenesis and progression of tumors. Therefore, FGFRtargeted therapy could represent a potential therapeutic option for breast cancer patients. Many FGFR inhibitors have been tested in clinical trials on multiple tumor types, including breast cancer $[5,7,36]$. These agents on trials include non-specific FGFR inhibitors Dovitinib, Ponatinib, Lucitanib, Ninedenib, Pazopanib and ARQ and selective inhibitors BGJ398, TAS120, Debio1347, and BAY1163877, AZD4547, JNJ42756493, LY2874455, and PRN1371. However, there appears currently limited single agent efficacy in breast cancer in trials reported to date $[37,38]$. There may be several potential reasons for this. FGFR-targeting therapy was proven effective in tumors where FGFR fusions are drivers, such as in cholangiocarcinoma [39-41]. However, FGFR fusions are rare in breast cancer. Previous studies have also suggested other potential drug resistance mechanisms responsible for escape from growth inhibitory effect of FGFR inhibitors, including signaling bypass [42-44]. Therefore, prospective selection of patients with specific FGFR aberrations is one of the major challenges in clinical trials of breast cancer. Among those known deleterious FGFR alterations, the aberrant alternative splicing of FGFR1 reported in this study might be used as a selection biomarker for FGFRtargeting therapeutics. Our in vitro data provide supporting evidence for this prospect. For example, breast cancer cells, particularly basal TNBCs, with high FGFR $1 \beta$ levels or a high FGFR1 $\beta /$ FGFR $1 \alpha$ ratio are more sensitive to FGFR inhibitors which not only block FGFR signaling activity also reduce FGFR $1 \beta$ expression.

ER has been reported to play an important role in tumorigenic transformation of human breast epithelial cells [45]. While the responsible molecular mechanisms are still under intensive investigation, we found in this study that exposure of $\mathrm{ER}^{+}$cells to estrogen increased FGFR1 $\beta$ expression. Similar to FGFR blockage that decreases FGFR1 $\beta$ levels, ER inactivation by ER antagonist also downregulates FGFR1 $\beta$ expression. Very interestingly, our immunoblotting data from drug treatment and gene depletion experiments demonstrate that regulation of FGFR $1 \beta$ expression by both FGFR and ER signaling share a same mechanism - through the same splicing repressor PTBP1. This novel mechanism provides a rationale for combinatorial therapy with FGFR inhibitors and ER inhibitors, both converging on FGFR $1 \beta$ via PTBP 1 . The synergy of this combination is proven by our in vitro testing. In addition, we may also consider combination with agents that modify PTBP1 expression. For example, we found that retinoid acid (RA) was capable of increasing PTBP1 levels leading to reduction of FGFR1 $\beta /$ FGFR $1 \alpha$ ratio in breast cancer cells (Supplementary Figure 8). Although PTBP1 is widely known as a repressor in regulation of alternative splicing, some groups reported that this trans-acting protein positively regulates FGFR $1 \beta$ splicing by mediating $\alpha$ exon deletion through specific intronic slicing sequences (ISS1, ISS2) flanking $\alpha$ exon region that encodes the autoinhibition IgI domain [46]. The inconsistency between these reports and our finding however needs to be further clarified. Other than PTBP1, another trans-splicing factor, serine/arginine-rich (SR) splicing factor 55 (SRp55), may also play a role in ER regulation of FGFR $1 \beta$ splicing in $\mathrm{ER}^{+}$breast cancer cells. Jin and Cote identified specific exonic splicing enhancers (ESE1, ESE2) in $\alpha$ exon, and found that interaction between these cis-elements and SRp55 protein controls $\alpha$ exon exclusion [47]. Knocking down SRp55 resulted in more production of $\alpha$ exon-excluded FGFR1 (FGFR1 $\beta$ ) than $\alpha$ exon-included one (FGFR $1 \alpha)$. Interestingly, it was found that activation of ER downregulated SRp55 levels in $\mathrm{ER}^{+}$MCF-7 cells [48]. SRp55 has been previously implicated in breast cancer, and depletion of SRp55 levels is associated with increased resistance to DNA damage [49]. However, we will pursue examining SRp55 involvement in ER regulation of FGFR1 splicing in the future. In summary, it is expected that in FGFR-targeting therapies of $\mathrm{ER}^{+}$breast cancer patients, simultaneous ER inactivation may produce synergistic therapeutic efficacy by reversing estragon-induced high FGFR1 $\beta /$ FGFR1 $\alpha$ ratio in the $\mathrm{ER}^{+}$breast cancer cells.

Although our study has characterized the pathological role of alternative FGFR1 splicing in breast cancer, further study is needed to determin if the FGFR isoforms can assist in idenfifying patients with FGFRdriven breast cancers and help therapeutic decision making.

\section{MATERIALS AND METHODS}

\section{Analysis of expression of FGFR1 variants in patients}

The Cancer Genome Atlas (TCGA) breast cancer level 3 database of total 803 breast cancer samples were used for bioinformatic analysis of expression of FGFR1 and its alternative splicing variants. TCGA BRCA RNASeq isoform expression data was downloaded from / rsrch1/bcb/batcheffects/STD_DATA/STANDARDIZED/ current/brca/rnaseqv2/illuminahiseq_rnaseqv2_isoform/ Level_3. The isoform expression was $\log 2$ (RSEM+ point one percentile). The transcript containing exon 3 (Che8:38287200-38287466) that encodes IgI domain is FGFR1 $\alpha$, otherwise is FGFR1 $\beta$. In amplified FGFR1 samples (copy number $\geq 4$ ) and non-amplified samples (copy number $<2.55$ ), $T$-test was used to test the difference of expression levels of FGFR1, FGFR $1 \alpha$ and FGFR1 $\beta$ between amplified and non-amplified samples. 
Anova and Kruskal Walis rank sum tests were used to test the difference of FGFR $1 \alpha$ and FGFR $1 \beta$ expression levels and their ratio respectively between 3 breast cancer subtypes, including basal, HER2-amplified (HER2 ${ }^{+}$), and luminal $\left(\mathrm{ER}^{+} / \mathrm{HER} 2^{-}\right.$and $\left.\mathrm{ER}^{+} / \mathrm{HER} 2^{-}\right)$. Out of the 803 samples, top $10 \%$ samples with high and low FGFR $1 \beta$ / FGFR $1 \alpha$ ratio and top $10 \%$ samples with high and low FGFR1 $\beta$ levels were used to identify differentially expressed genes (DEGs). Genes with very low counts ( $<30$ reads) were filtered out, which left 17,541 genes for DEG analysis. Unsupervised hierarchical clustering and principal component analysis (PCA) plot were used for quality assessment. 1,777 DEGs that have FDR 0.01 with fold changes larger than 2 smaller than $1 / 2$ were identified with generalized linear model (GLM) likelihood ratio test and visualized by heatmap. Association of canonical signaling pathways with DEGs was analyzed using Ingenuity Pathway Analysis (IPA) software (version 470319M).

\section{Cell lines, drugs and other reagents}

A panel of 14 breast cancer cell lines and one nontumor mammary epithelial cell line were obtained from ATCC, including BT-474, BT-549, CAMA1, HCC-38, HCC-1143, HCC-1569, MCF-7, MMDA-MB-134VII, MMDA-MB-157, MMDA-MB-231, MMDA-MB-361, MMDA-MB-436, MDA- MDA-MB-453, T47D, and MCF-10A. Breast cancer cell line MFM-223 cells were purchased from Sigma. All the breast cancer cell lines were cultured in Dulbecco's modified Eagle's medium/F-12 (DMEM) supplemented with 10\% fetal bovine serum at $37^{\circ}$ and humidified $5 \% \mathrm{CO}_{2}$. MCF-10A cells were cultured in complete mammary epithelial cell growth medium (MEGM) supplemented with growth factors and insulin (Lonza). To create FGFR $1 \alpha$ and FGFR $1 \beta$ variants, MCF-10A cells were infected with virus packaged from 293 cells using viral expression vectors pLenti-C-MycFGFR1 $\alpha$ (\#RC202080L1) and pLenti-C-Myc-FGFR1 $\beta$ (\#RC210629L1) plasmids as well as empty vector (\#PS100064) (OriGene, Rockville, MD). FGFR inhibitor BGJ-398 was purchased from Selleck Chemicals (Houston TX, USA). 17 $\beta$-estradiol and 4-hydroxytamoxifen were purchased from Sigma. Growth factors FGF2 and TGF- $\beta 1$ were purchased from R\&D Systems (Minneapolis, MN). BD Matrigel ${ }^{\mathrm{TM}}$ Basement Membrane Matrix Growth Factor Reduced was purchased from BD Biosciences (San Jose, CA). Immunoblotting antibodies purchased from Cell Signaling Technology (CST) include anti-FGFR1 (\#9740), anti-phospho-ERK ${ }_{1 / 2} /$ T202/Y204 (\#4370), anti$\mathrm{ERK}_{1 / 2}$ (\#9102), anti-phospho-MEK $/$ /S217/221 (\#9154), anti-MEK $_{1 / 2}$ (\#9126), anti-E-cadherin (\#3195), antiphospho-AKT/S473 (\#4060), anti-phospho-S6/S235/236 (\#4858), anti-phospho-4E-BP1/S65 (\#9456), and antiPTBP1 (\#57246). Anti- $\beta$-actin antibody (\#A5441) was purchased from Sigma. Secondary antibodies Goat-antiRabbit-Alexa Fluor-680 (\#A21076) and Goat-anti-MouseDylight-800 (\#610145-121) were purchased from Life Tech and Rockland Immunochemicals respectively.

\section{Western blot assay}

Cells were lysed in 2x Laemmli buffer, followed by protein concentration measurement using Pierce BCA protein assay Kit (ThermoFisher). After SDS-PAGE, proteins were transferred to a $0.2 \mu \mathrm{m}$ nitrocellulose membrane (Bio-Rad Laboratories). Membranes were blocked with $0.1 \%$ casein blocking buffer, followed by immunoblotting with the primary antibodies as described in Cell lines, Drugs and Reagents at room temperature overnight. After washing, the membrane was probed with the second antibodies with fluorescence conjugation. The immunoblots were visualized using the Odyssey IR imaging system (Li-Cor Biosciences).

\section{Cell viability assay}

Cells were seeded in 96-well plates at densities of $0.3-1.0 \times 10^{4}$ cells $/ 100 \mu \mathrm{l}$ per well in triplicate for each treatment dose. After adhering overnight, $100 \mu \mathrm{l}$ of drug at serially diluted concentrations were added to the wells and incubated at $37^{\circ} \mathrm{C}$ for 72 hours. Cells were fixed with $50 \%$ trichloroacetic (TCA) followed by staining with $0.4 \%$ sulforhodamine B (SRB) solution. OD values were read at $490 \mathrm{~nm}$ by plate reader Synergy 4 (BioTek). The half maximal inhibitory concentration $\left(\mathrm{IC}_{50}\right)$ was determined using GraphPad Prism v6.05 software.

\section{Colony formation assay}

Cells were seeded in 6-well plates at a density of 500-1000 cells per well in triplicate for each treatment group. Cells were cultured for 3 weeks. Culture medium was changed with fresh drugs twice a week. The cell colonies were fixed in 10\% formalin and stained with $0.05 \%$ crystal violet in $25 \%$ methanol. The stained colonies in the wells were scanned and total colony area and average colony size were quantitated using $\mathrm{NIH}$ ImageJ v.1.48 software.

\section{D-Matrigel assay}

Cells were seeded into 8-well glass chamber slides coated with growth factor reduced BD Matrigel ${ }^{\mathrm{TM}}$ Basement Membrane Matrix at 5000 cells/well in a complete MEGM medium containing 2\% Matrigel, in the presence or absence of FGF2 or BGJ-398. Refresh culture medium every 4 days with $2 \%$ Matrigel MEBM medium and drugs. Cells were cultured for 2 weeks. Photomicrograph of spherical structures formed on the Matrigel was performed. 


\section{Soft agar assay}

6-well plates were coated with $0.5 \%$ bottom agar (Difco Agar Noble, BD, \#214220). Cells were mixed with $0.35 \%$ top agar containing $10 \%$ FBS and seeded onto the bottom agar wells at 5000 cells/well. $1 \mathrm{ml}$ complete MEGM medium was added on top the agar. Cells were fed twice a week and cultured for 3 weeks. Colonies in the agar were stained with iodonitrotetrazolium chloride (INT) overnight, followed by colony photomicrograph.

\section{Wound healing assay}

When cells cultured in 12-well plates were confluent, a cross scratch was made on the cell layer with $1 \mathrm{ml}$ tip. Medium was changed to remove detached floating cells. Cells were cultured with or without BGJ398 treatment for 2 days to allow cell migration, followed by $10 \%$ formalin fixation and crystal violet staining. Photomicrograph of wound gap was performed, followed by quantitation using ImageJ. Relative fraction of wound gap was converted from wound gap area using a formula: wound gap area $=(100 / \%$ Area $) \times$ Total Area.

\section{Transwell invasion assay}

Transwell inserts (Corning, \#354578) were coated with basement membrane extract (BME) Matrigel (Corning, \#356234). Starved cells were seeded into the inserts at $5 \times 10^{4}$ cells / insert in $0.3 \mathrm{ml}$ serum-free medium. The inserts were assembled into wells of 24-well plates containing $0.5 \mathrm{ml}$ medium with $10 \%$ FBS. Cells were cultured for 24 hours. Cells on the up-surface of the inserts were removed by scrubbing with cotton swabs. Cells that invaded through the BME were fixed on the down-surface of the inserts with $10 \%$ formalin, followed by staining with $0.4 \%$ crystal violet. The stained cells were imaged by inverted microscope at X10 magnification. Cells numbers were counted per image field. 9 fields were quantitated for each group.

\section{RT-PCR assay}

Total RNA was extracted from cell lysates using an RNeasy Mini Kit (Qiagen) and quantitated by Qubit RNA BR Assay (Invitrogen). cDNA was prepared using a High Capacity cDNA Reverse Transcription Kit (Applied Biosystems), followed by PCR using a TaqMan ${ }^{\circledR}$ Universal PCR Master Mix (Applied Biosystems). PCR primers "5'-TTCTGGGCTGTGCTGGTCAC (forward)" and "5'-CTTGTAGACGATGACCGACC (reverse)" were used to amplify FGFR1 variants.

\section{ChIP assay}

MFM-223 cells cultured in $100-\mathrm{mm}$ petri dishes were treated with $1 \%$ formaldehyde for $10 \mathrm{~min}$ to cross- link chromatin. Chromatin immunoprecipitation (ChIP) assays were performed following the protocol of a ChIP assay kit (Sigma, \#17-295). Briefly, the cells were scraped and sonicated on ice to shear chromatin DNA down to $0.2-$ to $1.0-\mathrm{kb}$ fragments. The sonicated cell supernatant was precleared with a protein A agarose-salmon sperm DNA slurry, and then anti-PTBP1 antibody was added to the supernatant at $4{ }^{\circ} \mathrm{C}$ overnight with rotation, followed by incubation with fresh protein A agarose beads for $1 \mathrm{~h}$ at $4^{\circ} \mathrm{C}$ for precipitation. The specific protein-DNA complex was reversely cross-linked, and DNA fragments were purified. With these DNAs as templates, PCR were performed to amplify ISS region using primers 5 '-caactccggacacaaagaag and 5'-catcacttactggaggctac.

\section{Abbreviations}

FGFR: fibroblast growth factor receptor; TGF $\beta$ : transforming growth factor- $\beta$; ER: estrogen receptor; PTBP1: polypyrimidine tract-binding protein 1; TNBC: triple negative breast cancer; TCGA: The Cancer Genome Atlas; SRB: sulforhodamine B; BME: basement membrane extract; EMT: epithelial-to-mesenchymal transition; ESE: exonic splicing enhancers; DEGs: differently expressed genes; FDR: false discovery rate; IPA: Ingenuity Pathway Analysis.

\section{Author contributions}

Dr. Funda Meric-Bernstam is the senior author, conceived and designed the study, interpreted the data, and edited the manuscript. Dr. Ming Zhao performed and analyzed most of experiments, interpreted and analyzed the data, made the figures and wrote the manuscript. Dr. Ming-Lei Zhuo performed RT-PCR experiments. Drs. Xiaofeng Zheng, and Xiaoping Su performed Analysis of expression of FGFR1 variants in patients. All authors read and approved the final manuscript.

\section{ACKNOWLEDGMENTS}

We thank Ms. Elena Vess for assistance in preparing and submitting the manuscript.

\section{CONFLICTS OF INTEREST}

Drs. Ming Zhao, Ming-Lei Zhuo, Xiaofeng Zheng, and Xiaoping Su have nothing to disclose.

Dr. Meric-Bernstam reports grants from Novartis, AstraZeneca, Calithera, Bayer, Jounce, CytoMx, eFFECTOR, Zymeworks, PUMA Biotechnology, Curis, Millennium, Daiichi Sankyo, Abbvie, Guardant Health, and Takeda; grants and travel related fees from Taiho, Genentech, Debiopharm Group, and Pfizer; and served as a consultant to Inflection Biosciences, Pieris, Darwin Health, GRAIL, Clearlight Diagnostics, Dialectica, 
Sumitomo Dainippon, Spectrum, Samsung Bioepis, Aduro, OrigiMed, Xencor, Jackson Laboratory, and Mersana.

\section{FUNDING}

This work was supported by the Sheikh Khalifa Al Nahyan Ben Zayed Institute for Personalized Cancer Therapy, the Nellie B. Connally Breast Cancer Research Endowment, Cancer Prevention Research Institute of Texas (CPRIT) Precision Oncology Decision Support Core RP150535, and the MD Anderson Cancer Center Support grant (P30 CA016672).

\section{REFERENCES}

1. Siegel R, Naishadham D, Jemal A. Cancer statistics, 2012. CA Cancer J Clin. 2012; 62:10-29.

2. Torre LA, Bray F, Siegel RL, Ferlay J, Lortet-Tieulent J, Jemal A. Global cancer statistics, 2012. CA Cancer J Clin. 2015; 65:87-108.

3. Chae YK, Ranganath K, Hammerman PS, Vaklavas C, Mohindra N, Kalyan A, Matsangou M, Costa R, Carneiro B, Villaflor VM, Cristofanilli M, Giles FJ. Inhibition of the fibroblast growth factor receptor (FGFR) pathway: the current landscape and barriers to clinical application. Oncotarget. 2017; 8:16052-16074. https://doi.org/10.18632/oncotarget.14109.

4. Babina IS, Turner NC. Advances and challenges in targeting FGFR signalling in cancer. Nat Rev Cancer. 2017; $17: 318-332$

5. De Luca A, Frezzetti D, Gallo M, Normanno N. FGFRtargeted therapeutics for the treatment of breast cancer. Expert Opin Investig Drugs. 2017; 26:303-311.

6. Fearon AE, Gould CR, Grose RP. FGFR signalling in women's cancers -- IIIb, IIIc, amplificvation in BC. Int J Biochem Cell Biol. 2013; 45:2832-2842.

7. Wang S, Ding Z. Fibroblast growth factor receptors in breast cancer. Tumour Biol. 2017; 39:1010428317698370.

8. Elbauomy Elsheikh S, Green AR, Lambros MB, Turner NC, Grainge MJ, Powe D, Ellis IO, Reis-Filho JS. FGFR1 amplification in breast carcinomas: a chromogenic in situ hybridisation analysis. Breast Cancer Res. 2007; 9:R23.

9. Fumagalli D, Wilson TR, Salgado R, Lu X, Yu J, O’Brien C, Walter K, Huw LY, Criscitiello C, Laios I, Jose V, Brown $\mathrm{DN}$, Rothe F, et al. Somatic mutation, copy number and transcriptomic profiles of primary and matched metastatic estrogen receptor-positive breast cancers. Ann Oncol. 2016; 27:1860-1866.

10. Turner N, Pearson A, Sharpe R, Lambros M, Geyer F, Lopez-Garcia MA, Natrajan R, Marchio C, Iorns E, Mackay A, Gillett C, Grigoriadis A, Tutt A, et al. FGFR1 amplification drives endocrine therapy resistance and is a therapeutic target in breast cancer. Cancer Res. 2010; 70:2085-2094.

11. Ghigna C, Valacca C, Biamonti G. Alternative splicing and tumor progression --- review with FGFR1. Curr Genomics. 2008; 9:556-570.

12. Martinez-Montiel N, Anaya-Ruiz M, Perez-Santos M, Martinez-Contreras RD. Alternative splicing in breast cancer and the potential development of therapeutic tools --- review with FGFR1. Genes (Basel). 2017; 8.

13. Kalinina J, Dutta K, Ilghari D, Beenken A, Goetz R, Eliseenkova AV, Cowburn D, Mohammadi M. The alternatively spliced acid box region plays a key role in FGF receptor autoinhibition --- autoinhibition of $\mathrm{IgI}$ and $\mathrm{AB}$ box. Structure. 2012; 20:77-88.

14. Olsen SK, Ibrahimi OA, Raucci A, Zhang F, Eliseenkova AV, Yayon A, Basilico C, Linhardt RJ, Schlessinger J, Mohammadi M. Insights into the molecular basis for fibroblast growth factor receptor autoinhibition and ligandbinding promiscuity. Proc Natl Acad Sci U S A. 2004; 101:935-940.

15. Morrison RS, Yamaguchi F, Saya H, Bruner JM, Yahanda AM, Donehower LA, Berger M. Basic fibroblast growth factor and fibroblast growth factor receptor I are implicated in the growth of human astrocytomas -- Ib in glioblastoma, Ia in normal brain. J Neurooncol. 1994; 18:207-216.

16. Wang F, Kan M, Yan G, Xu J, McKeehan WL. Alternately spliced NH2-terminal immunoglobulin-like Loop I in the ectodomain of the fibroblast growth factor (FGF) receptor 1 lowers affinity for both heparin and FGF-1 --- b more affinity to FGFs. J Biol Chem. 1995; 270:10231-10235.

17. Yamaguchi F, Saya H, Bruner JM, Morrison RS. Differential expression of two fibroblast growth factorreceptor genes is associated with malignant progression in human astrocytomas --- FGFR1b more malignant in astrocytoma. Proc Natl Acad Sci U S A. 1994; 91:484-488.

18. Karajannis MA, Vincent L, Direnzo R, Shmelkov SV, Zhang F, Feldman EJ, Bohlen P, Zhu Z, Sun H, Kussie P, Rafii $\mathrm{S}$. Activation of FGFR1beta signaling pathway promotes survival, migration and resistance to chemotherapy in acute myeloid leukemia cells --- FGFR1b most in AML cells and induced by FGF2. Leukemia. 2006; 20:979-986.

19. Tomlinson DC, Knowles MA. Altered splicing of FGFR1 is associated with high tumor grade and stage and leads to increased sensitivity to FGF1 in bladder cancer ---- b binds more FGFs, more $b$ with tumor stage and grade. Am J Pathol. 2010; 177:2379-2386.

20. Alizadeh M, Gelfman CM, Bench SR, Hjelmeland LM. Expression and splicing of FGF receptor mRNAs during APRE-19 cell differentiation in vitro ----- FGFR1b/a ratio decrease as eye cells differentation. Invest Ophthalmol Vis Sci. 2000; 41:2357-2362.

21. Jiao J, Greendorfer JS, Zhang P, Zinn KR, Diglio CA, Thompson JA. Alternatively spliced FGFR-1 isoform signaling differentially modulates endothelial cell responses 
to peroxynitrite ---- FGFR1a, b overexpression in brain cells, induce growth, oposite effect on cell death. Arch Biochem Biophys. 2003; 410:187-200.

22. Luqmani YA, Mortimer C, Yiangou C, Johnston CL, Bansal GS, Sinnett D, Law M, Coombes RC. Expression of 2 variant forms of fibroblast growth factor receptor 1 in human breast --- IIIb, IIIc expression in BC. Int J Cancer. 1995; 64:274-279.

23. Wendt MK, Taylor MA, Schiemann BJ, Sossey-Alaoui K, Schiemann WP. Fibroblast growth factor receptor splice variants are stable markers of oncogenic transforming growth factor betal signaling in metastatic breast cancers --- Wendt et al. Breast Cancer Res. 2014; 16:R24.

24. Debnath J, Muthuswamy SK, Brugge JS. Morphogenesis and oncogenesis of MCF-10A mammary epithelial acini grown in three-dimensional basement membrane cultures. Methods. 2003; 30:256-268.

25. Qu Y, Han B, Yu Y, Yao W, Bose S, Karlan BY, Giuliano AE, Cui X. Evaluation of MCF10A as a reliable model for normal human mammary epithelial cells -- 3D model. PLoS One. 2015; 10:e131285.

26. Li Q, Mattingly RR. Restoration of E-cadherin cellcell junctions requires both expression of E-cadherin and suppression of ERK MAP kinase activation in Rastransformed breast epithelial cells -- E-cad expression. Neoplasia. 2008; 10:1444-1458.

27. Yuki K, Yoshida Y, Inagaki R, Hiai H, Noda M. E-cadherindownregulation and RECK-upregulation are coupled in the non-malignant epithelial cell line MCF10A but not in multiple carcinoma-derived cell lines -- TGFb, E-cad. Sci Rep. 2014; 4:4568.

28. Maeda M, Johnson KR, Wheelock MJ. Cadherin switching: essential for behavioral but not morphological changes during an epithelium-to-mesenchyme transition -- TGFb, E-cad, EMT. J Cell Sci. 2005; 118:873-887.

29. Sauliere J, Sureau A, Expert-Bezancon A, Marie J. The polypyrimidine tract binding protein (PTB) represses splicing of exon $6 \mathrm{~B}$ from the beta-tropomyosin pre-mRNA by directly interfering with the binding of the U2AF65 subunit. Mol Cell Biol. 2006; 26:8755-8769.

30. Ling JP, Chhabra R, Merran JD, Schaughency PM, Wheelan SJ, Corden JL, Wong PC. PTBP1 and PTBP2 Repress Nonconserved Cryptic Exons. Cell Rep. 2016; 17:104-113.

31. Clower CV, Chatterjee D, Wang Z, Cantley LC, Vander Heiden MG, Krainer AR. The alternative splicing repressors hnRNP A1/A2 and PTB influence pyruvate kinase isoform expression and cell metabolism. Proc Natl Acad Sci U S A. 2010; 107:1894-1899.

32. Bhat-Nakshatri P, Song EK, Collins NR, Uversky VN, Dunker AK, O'Malley BW, Geistlinger TR, Carroll JS, Brown M, Nakshatri H. Interplay between estrogen receptor and AKT in estradiol-induced alternative splicing -- ER, Akt regulate FR2 splicing. BMC Med Genomics. 2013; 6:21.
33. Perou CM, Sorlie T, Eisen MB, van de Rijn M, Jeffrey SS, Rees CA, Pollack JR, Ross DT, Johnsen H, Akslen LA, Fluge O, Pergamenschikov A, Williams C, et al. Molecular portraits of human breast tumours. Nature. 2000; 406:747-752.

34. Gru AA, Allred DC. FGFR1 amplification and the progression of non-invasive to invasive breast cancer. Breast Cancer Res. 2012; 14:116.

35. Wang W, Meng Y, Dong B, Dong J, Ittmann MM, Creighton CJ, Lu Y, Zhang H, Shen T, Wang J, Rowley DR, Li Y, Chen F, et al. A versatile tumor gene deletion system reveals a crucial role for FGFR1 in breast cancer metastasis. Neoplasia. 2017; 19:421-428.

36. Porta R, Borea R, Coelho A, Khan S, Araujo A, Reclusa P, Franchina T, Van Der Steen N, Van Dam P, Ferri J, Sirera R, Naing A, Hong D, Rolfo C. FGFR a promising druggable target in cancer: Molecular biology and new drugs -Everything. Crit Rev Oncol Hematol. 2017; 113:256-267.

37. Mayer IA, Arteaga CL, Nanda R, Miller KD, Jhaveri K, Brufsky AM, Rugo H, Yardley DA, Vahdat LT, Sadeghi S, Audeh MW, Rolfe L, Litten J, et al. A phase 2 openlabel study of lucitanib in patients (pts) with FGF aberrant metastatic breast cancer (MBC). Cancer Research. 2017; 77.

38. Andre F, Bachelot T, Campone M, Dalenc F, Perez-Garcia JM, Hurvitz SA, Turner N, Rugo H, Smith JW, Deudon S, Shi M, Zhang Y, Kay A, et al. Targeting FGFR with dovitinib (TKI258): preclinical and clinical data in breast cancer. Clin Cancer Res. 2013; 19:3693-3702.

39. Javle M, Lowery M, Shroff RT, Weiss KH, Springfeld C, Borad MJ, Ramanathan RK, Goyal L, Sadeghi S, Macarulla T, El-Khoueiry A, Kelley RK, Borbath I, et al. Phase II Study of BGJ398 in Patients With FGFR-Altered Advanced Cholangiocarcinoma. J Clin Oncol. 2018; 36:276-282.

40. Voss MH, Hierro C, Heist RS, Cleary JM, Meric-Berstam F. Debio 1347, an oral FGFR inhibitor: results from a first-inhuman, phase I dose-escalation study in patients with FGFR genomically activated advanced solid tumors. J Clin Oncol. 2017; 35 .

41. Goyal L, Arkenau HT, Tran B, Soria JC. Early clinical efficacy of TAS-120, a covalently bound FGFR inhibitor, in patients with cholangiocarcinoma. Annals of Oncology. 2017; 28.

42. Herrera-Abreu MT, Pearson A, Campbell J, Shnyder SD, Knowles MA, Ashworth A, Turner NC. Parallel RNA interference screens identify EGFR activation as an escape mechanism in FGFR3-mutant cancer. Cancer Discov. 2013; 3:1058-1071.

43. Kotani H, Ebi H, Kitai H, Nanjo S, Kita K, Huynh TG, Ooi A, Faber AC, Mino-Kenudson M, Yano S. Co-active receptor tyrosine kinases mitigate the effect of FGFR inhibitors in FGFR1-amplified lung cancers with low FGFR1 protein expression. Oncogene. 2016; 35:3587-3597.

44. Wang J, Mikse O, Liao RG, Li Y, Tan L, Janne PA, Gray NS, Wong KK, Hammerman PS. Ligand-associated ERBB2/3 activation confers acquired resistance to FGFR 
inhibition in FGFR3-dependent cancer cells. Oncogene. 2015; 34:2167-2177.

45. Yusuf R, Frenkel K. Morphologic transformation of human breast epithelial cells MCF-10A: dependence on an oxidative microenvironment and estrogen/epidermal growth factor receptors. Cancer Cell Int. 2010; 10:30.

46. Bruno IG, Jin W, Cote GJ. Correction of aberrant FGFR1 alternative RNA splicing through targeting of intronic regulatory elements ---- inhibit ISS (intronic silencing seq) of a-exon to produce more FGFR1a, with more Caps3, 7 activity. Hum Mol Genet. 2004; 13:2409-2420.
47. Jin W, Cote GJ. Enhancer-dependent splicing of FGFR1 alpha-exon is repressed by RNA interference-mediated down-regulation of SRp55 ---- SRp55. Cancer Res. 2004; 64:8901-8905.

48. Lal S, Allan A, Markovic D, Walker R, Macartney J, Europe-Finner N, Tyson-Capper A, Grammatopoulos DK. Estrogen alters the splicing of type 1 corticotropin-releasing hormone receptor in breast cancer cells -- E2 reduce SRp55 in ER+ cells. Sci Signal. 2013; 6:ra53.

49. Grammatopoulos DK. CRH-R splicing in estrogen-sensitive breast cancer -- ER regulate SRp55 in ER+ BC. Cell Cycle. 2014; 13:687-688. 